\title{
Fatty acid profile and oxidative stability of egg yolks from hens under different production systems
}

\author{
D. Mierliță\# \\ University of Oradea, Department of Animal Science, Oradea City, 410087, Romania
}

(Received 31 October 2019; Accepted 4 January 2020; First published online 10 April 2020)

\begin{abstract}
Copyright resides with the authors in terms of the Creative Commons Attribution 4.0 South African License.
See: http://creativecommons.org/licenses/by/4.0/za

Condition of use: The user may copy, distribute, transmit and adapt the work, but must recognize the authors and the South African Journal of Animal Science.
\end{abstract}

\begin{abstract}
This study was carried out to compare the egg quality, fatty acid (FA) profiles, and oxidative stability of yolks from hens maintained in cages and fed a conventional diet (CON), those fed a conventional diet with free access to outdoor grassy area (5 $\mathrm{m}^{2} /$ hens) under free-range conditions (FR), and those fed an organic diet and free access to outdoor grassy area $\left(10 \mathrm{~m}^{2} / \mathrm{hens}\right)$ under in organic system (ORG). Heavier eggs were produced by CON, while percentages of yolk and eggshell were greater in eggs of FR and ORG hens. The FR and ORG hens produced eggs that contained significantly more monounsaturated fatty acids (MUFAs) but less polyunsaturated fatty acids (PUFAs) than CON hens. Eggs from FR and ORG hens had a lower concentration of PUFA $n-6$ because of less C18:2 n-6 (linoleic acid) and a higher percentage of PUFA $n-3$ (eicosapentaenoic acid). Consequently, the ratio of PUFA $n-6$ to $n-3$ for eggs from FR and ORG hens was healthier for consumers compared with CON. However, eggs from the ORG hens had a similar FA profile to those from the FR hens. No significant differences were noted in hypocholesterolaemic (HI), atherogenic (Al) and thrombogenic indexes. Antioxidant concentration was greatest in eggs from ORG hens (retinol-14.32 $\mu \mathrm{g} / \mathrm{g}$ and $\alpha$-tocopherol-98.7 $\mu \mathrm{g} / \mathrm{g} / \mathrm{yolk}$ ). Thus, the oxidative stability of eggs measured after storage at $4^{\circ} \mathrm{Cfor} 15$ or 30 days was improved. The best eggs in terms of nutritional value were from the ORG system in which hens lived in their natural environment.
\end{abstract}

Keywords: antioxidants, conventional production, egg quality, free range production, malonaldehyde, organic production

\#Corresponding author: dadi.mierlita@yahoo.com

\section{Introduction}

Today consumers are becoming more concerned about animal welfare, the quality of animal products, and food safety. In the effort to meet the demands of consumers, alternative production systems have become used more widely and advertised in product marketing. It is argued that better rearing practices enhance nutrient content of eggs (Rizzi et al., 2006). The most common rearing system for laying hens is battery cages, which were modified by the European Union (EU) in 2012 to furnished cages to provide at least $750 \mathrm{~cm}^{2}$ per hen. Alternative rearing methods include barn, FR and ORG systems (Tufarelli et al., 2018). Hens on a barn floor are reared free of cages, but are kept entirely indoors. In a FR system, hens are allowed access to the outside (Lordelo et al., 2017). Organic eggs are produced by hens that are reared in a FR production system and fed organically produced feed that is free of genetically modified organisms and synthetic additives (EU, 1999).

Outdoor systems are sustainable alternatives for poultry production in which laying hens are able to ingest nutrients from pasture and weeds, earthworms and insects, which are rich in n-3 FAs, vitamins and minerals and compounds such as carotenoids, and tocopherol (Moyle et al., 2014). Research has shown that people who consume extra n-3 FAs, that is, $\alpha$-linolenic acid (ALA) (18:3n-3), eicosapentaenoic acid (EPA) (20:5 n-3), and docosahexaenoic acid (DHA) (22:6n-3), may have reduced incidences of coronary heart disease and overall mortality (Simopoulos, 2000).

Eggs from ORG and FR systems tend to have less total cholesterol and more vitamins $A$ and $E$, are high in omega-3FAs, and have an improved ratio of omega-6 to omega-3 FAs (Anderson, 2011). Studies demonstrated that hens with access to high-quality pasture had eggs with at least twice as much vitamin $A$ 
and $\mathrm{E}$ and omega-3 FAs, and more intense yolk colour compared with hens with no access to pasture (Mugnai et al., 2009). These eggs meet the expectations of consumers that are willing to pay more for eggs from FR and ecological farms, assuming that such systems improve not only the welfare of hens, but also the quality of the eggs (Sokołowicz et al., 2018).

Wynn et al. (2016) showed that there is a small and non-significant difference in FA content of eggs, no matter whether they were produced by hens in organic or conventionally housed systems. Much of the published research to date is still contradictory as to whether organically reared and FR eggs are more beneficial to health than conventionally produced eggs and this conflicting information leaves consumers confused.

Alternative production systems could affect the quality features and nutritional composition of eggs (Lopez-Bote et al., 1998; Küçükyılmaz et al., 2012). However, there has been little research on the influence of production systems on FA profile, health lipid quality, and oxidative stability of eggs during storage. Consequently, the broad objective of the current study was to assess quality parameters (weight, egg components, cholesterol, and antioxidant content), FA profile, and lipid quality in table eggs from hens raised in CON, FR, and ORG production systems. As stated, high levels of PUFAs in eggs are desirable for their nutritional quality, but make it vulnerable to oxidation. Accordingly, the secondary objective of the study was to examine the oxidative stability of yolk lipids in relationship to the FA profile and antioxidant (retinol and $\alpha$ tocopherol) concentration of eggs throughout a 30-day refrigerated storage period.

\section{Materials and Methods}

Prior to its initiation, the project was reviewed and approved by the University of Oradea Ethics Committee. After a pre-trial period of adaptation to the environment and diet, 120 Tetra-SL LL (Granja Gibert, S.A., Cambrils, Spain) laying hens aged 26 weeks were divided into three groups of 40 hens each. The hens were allocated to obtain groups that were homogeneous in terms of weight and egg production. The hens were monitored clinically throughout the trial and their behaviour was observed constantly. The experiment lasted eight weeks, from 28 to 36 weeks old. During the trial, environmental temperature in the housing was set at $22-24{ }^{\circ} \mathrm{C}$. A lighting schedule of 16 hours (06h00 to 22h00) of light and 8 hours of darkness was used.

Hens from the CON group were kept in enriched cages $(120 \times 55 \times 45 \mathrm{~cm})$, each housing eight hens per cage with a stocking density of $825 \mathrm{~cm}^{2}$ of floor space/hen. The remaining two groups were kept indoors on litter in a poultry house $\left(6\right.$ hens $\left./ \mathrm{m}^{2}\right)$ with free access to two outdoor grassy areas of $200 \mathrm{~m}^{2}$ for the FR group ( $\left.5 \mathrm{~m}^{2} / \mathrm{bird}\right)$, and $400 \mathrm{~m}^{2}$ for the ORG group $\left(10 \mathrm{~m}^{2} / \mathrm{bird}\right)$. The indoor space was provided with nests (one per five hens), circular hanging feeders, and a bell drinker. Drinkers and feeders were also available in the outdoor area.

Birds of group CON and FR were fed ad libitum with a commercial mixed diet. Hens in the ORG group were given organic feed ad libitum. Conventional and organic feed mixtures were prepared with maize, wheat, soybean meal, lupine seed, sunflower meal and sunflower oil (Table 1). Similar ingredients were used when formulating diets to avoid discrepancies in ingredients and nutrient compositions between systems. At least $90 \%$ of the dry matter content of the organic feed mixture was provided from organically grown ingredients (EC Regulation 834/2007). Genetically modified soybean meal was the only conventional feed ingredient in the organic feed mixture. The diet for ORG hens was complete without the addition of synthetic amino acids. The diets were iso-energetic and iso-nitrogenous, and drinking water was always available. In the FR and ORG systems hens were able to supplement their diets with vegetation and small fauna. When the hens were 30,33 , and 36 weeks old, samples of grass were cut from random locations in the areas in which the hens were pastured. The chemical compositions of the feed and grass were determined according to AOAC (1999).

To evaluate the quality of eggs from these rearing systems, 30 eggs were randomly sampled from the hens of every group when the hens were 30,33 , and 36 weeks old. Eggs were evaluated after 24 hours of refrigerated storage at $4{ }^{\circ} \mathrm{C}$. Assessment of egg quality was based on egg weight $(\mathrm{g})$, and percentages of yolk, albumen, and shell in the whole egg. Egg weight was determined by weighing each egg. Percentage contents of egg morphological components (yolk, albumen, and shell) were calculated based on their weights measured individually.

Eggs were collected for three consecutive days from all groups (a total of 270 eggs; that is, 90 eggs per group and 30 eggs per day) in week 33 . The eggs were stored in a cold room at $4{ }^{\circ} \mathrm{C}$. On days 0,15 , and 30 of storage, 10 eggs were selected randomly from each group. The length of storage time was selected to simulate the probable duration of consumer storage of shell eggs. Egg yolks were separated and an aliquot was taken for a-tocopherol and retinol concentration and lipid oxidation products, measured as thiobarbituric acid reactive substances (TBARS). 
Fatty acid profiles of the egg yolks, diet, and grass samples were quantified as methyl esters by gas chromatography (AOAC, 1999). Fatty acids ere extracted with a chloroform:methanol mixture in a 2:1 ratio (Folch et al., 1957). The solvent was evaporated, and the residue was saponified $(0.5 \mathrm{~N}$ sodium hydroxide $(\mathrm{NaOH})$ in methanol) and esterified boron trifluoride $\left(\mathrm{BF}_{3}\right)$ in methanol). The fatty acid methyl esters were extracted in hexane and analysed with a Shimadzu GC-2010 gas chromatograph (Shimadzu Corporation, Tokyo, Japan) equipped with a DB-23 column ( $60 \mathrm{~m} \times 0.25 \mathrm{~mm}$ in diameter and $0.25 \mu \mathrm{m}$ film thickness). Column and detector temperatures were $190^{\circ} \mathrm{C}$ and $240{ }^{\circ} \mathrm{C}$, respectively. The carrier gas was helium at 1.0 $\mathrm{ml} / \mathrm{min}$ ratio. The temperature of injection port was $230^{\circ} \mathrm{C}$ with the split ratio of $1: 80$. The temperature programme was $80^{\circ} \mathrm{C}$ for 5 minutes, $200^{\circ} \mathrm{C}$ for 30 minutes, and $230^{\circ} \mathrm{C}$ for 15 minutes (Mierliță, 2019). Fatty acid methyl esters were identified using external standards (Supelco 37 Component FAME mix, Supelco Bellefonte, PA, USA), and the FA contents were calculated from the peak area of the corresponding FA in relation to the total area of all peaks.

Table 1 Formulation and nutrient composition of conventional and organic diets and grass for Tetra-SL LL laying hens

\begin{tabular}{|c|c|c|c|}
\hline & Conventional diet & Organic diet & Grass \\
\hline \multicolumn{4}{|l|}{ Ingredient ( $\mathrm{g} / \mathrm{kg})$} \\
\hline Maize & 409.10 & 344.30 & \\
\hline Wheat & 100.00 & 100.00 & \\
\hline Soybean meal ( $46 \%$ crude protein) & 91.00 & 76.00 & \\
\hline Sunflower meal ( $31 \%$ crude protein) & 50.00 & 100.00 & \\
\hline Lupine seed (38\% crude protein) & 200.00 & 200.00 & \\
\hline Dried alfalfa ( $18 \%$ crude protein) & - & 30.00 & \\
\hline Sunflower oil & 40.00 & 40.00 & \\
\hline DL-Methionine & 1.10 & - & \\
\hline Choline chloride & 0.50 & - & \\
\hline Sodium bicarbonate & 0.50 & - & \\
\hline Limestone & 88.00 & 89.50 & \\
\hline Dicalcium phosphate & 14.80 & 15.20 & \\
\hline Salt & 2.50 & 2.50 & \\
\hline Vitamin-mineral premix ${ }^{1}$ & 2.50 & 2.50 & \\
\hline \multicolumn{4}{|l|}{ Calculated chemical composition } \\
\hline Dry matter (DM) $(\mathrm{g} / \mathrm{kg})$ & 891.70 & 886.20 & 224.70 \\
\hline Metabolizable energy (MJ/kg) & 11.72 & 11.71 & - \\
\hline Crude protein $(\mathrm{CP})(\%)$ & 17.21 & 17.09 & $16.80(\%$ of $\mathrm{DM})$ \\
\hline Crude fat (\%) & 7.32 & 7.14 & $3.72(\%$ of $\mathrm{DM})$ \\
\hline Crude fibre (\%) & 4.86 & 5.72 & $21.3(\%$ of $\mathrm{DM})$ \\
\hline Lysine (\%) & 0.85 & 0.84 & - \\
\hline Methionine + cysteine (\%) & 0.66 & 0.63 & - \\
\hline Calcium (\%) & 3.76 & 3.76 & - \\
\hline Total phosphorus (\%) & 0.65 & 0.65 & - \\
\hline
\end{tabular}

${ }^{1}$ Providing per $\mathrm{kg}$ of diet: vitamin $\mathrm{A}: 11000 \mathrm{IU}$, vitamin $\mathrm{D}_{3}: 2500 \mathrm{IU}$, vitamin $\mathrm{E}: 25 \mathrm{IU}$, vitamin $\mathrm{K}_{3}: 3.0 \mathrm{mg}$, vitamin $\mathrm{B}_{1}: 3 \mathrm{mg}$, vitamin $B_{2}: 6 \mathrm{mg}$, niacin: $25 \mathrm{mg}$, calcium pantothenate: $8 \mathrm{mg}$, vitamin $\mathrm{B}_{6}: 4 \mathrm{mg}$, vitamin $\mathrm{B}_{12}: 0.012 \mathrm{mg}$, folic acid: $1.7 \mathrm{mg}$, manganese: $80 \mathrm{mg}$, zinc: $50 \mathrm{mg}$, iron: $50 \mathrm{mg}$, copper: $6 \mathrm{mg}$, cobalt: $0.2 \mathrm{mg}$, iodine: $0.5 \mathrm{mg}$, selenium: $0.10 \mathrm{mg}$, choline chloride: $130 \mathrm{mg}$

Egg yolks were analysed for total cholesterol content by the Washburn and Nix method (1974), which involves potassium hydroxide $(\mathrm{KOH})(60 \mathrm{~g} / 100 \mathrm{~mL})$ saponification and ethyl ether extraction of the cholesterol. The sample was subjected to chromatographic analysis under these conditions: length of DEXD 
glass column, $1 \mathrm{~m}$; internal diameter, $4 \mathrm{~mm}$; film thickness, $0.25 \mu \mathrm{m}$; temperature of detector, $300{ }^{\circ} \mathrm{C}$; temperature of injector, $290{ }^{\circ} \mathrm{C}$; temperature of column, $260^{\circ} \mathrm{C}$; carrier gas, argon; flow rate, $50 \mathrm{~cm} / \mathrm{min}$ (Mierliță, 2019). Egg yolk cholesterol content was calculated and expressed as milligrams per gram of yolk.

For analysis of carotene in the diets and grass samples, ethanol:methanol:tetrahydrofuran (75:20:5) was used as a high-performance liquid chromatography (HPLC) buffer (Mierliță et al., 2017). The flow rate was at $1 \mathrm{~mL} / \mathrm{min}$ and the injection volume was $100 \mu \mathrm{L}$. The wave length for detection was $450 \mathrm{~nm}$. External standards were used to quantify the $\beta$-carotene.

Tocopherol was analysed similarly to the extracted carotene. The extracts were partitioned in a separatory funnel with water, hexane and saline solution; the hexane phase was evaporated to dry-ness. The residue obtained was diluted with tert-butyl methyl ether/methanol, filtered (PTFE membrane filters, 0.45 $\mu \mathrm{m}$ ), after which separation of the tocopherol was by HPLC equipped with an Altech C18 column (length 15 $\mathrm{cm}$, $4.6 \mathrm{~mm}$ internal diameter and particle size $3 \mu \mathrm{m}$ ). The mobile phase was acetonitrile:methanol (85:5)/isopropanol 90/10. Detection wavelength for $\alpha$-tocopherol was set at $290 \mathrm{~nm}$. Injecting known amounts of $\alpha$-tocopherol (Sigma-Aldrich) standard produced a realized standard curve. Quantitative analysis of $\alpha$-tocopherol in the samples was performed by HPLC Millennium software using peak area measurement and the standard curve (Mierliță et al., 2017).

Egg yolks were analysed for retinol and tocopherol contents using a HPLC procedure. Extraction of fat-soluble vitamins was done with a mixture of diethyl ether and petroleum ether (1:1), in aliquots of $20 \mathrm{~mL}$. The ether phase, after separation, was saponified with methanolic $\mathrm{KOH}$ solution $(10 \%)$, after which the vitamins were extracted in hexane, washed with water in a separator funnel, and evaporated to dryness. The determination of retinol was conducted in a first stage using standardized solutions of total-trans-retinol (10 to $80 \mathrm{mg} / \mathrm{mL}$ ). Standard solutions (Sigma-Aldrich) and samples were injected into a Parkin-Elmer LC-295 system, equipped with an Altech C18 column $(15 \mathrm{~cm}$ length, $4.6 \mathrm{~mm}$ internal diameter and $3 \mu \mathrm{m}$ particle size). The mobile phase consisted of acetonitrile/methanol (85:15), with the addition of 2-propanol (30\%) after 8 min.

2-thiobarbituric acid (TBA) was measured from the malonaldehyde (MDA) that formed in fresh eggs and those that were refrigerated as described by Cherian et al. (1996). Egg yolk samples $(2 \mathrm{~g})$ were weighed into test tubes, and perchloric acid was added. The samples were homogenized for 15 seconds. Butylated hydroxytoluene was then added to each sample during homogenization to control lipid oxidation. The homogenate was filtered, the filtrate $(2 \mathrm{~mL})$ was mixed with $2 \mathrm{~mL}$ of $20 \mathrm{mM}$ TBA in distilled water, and the mixture was incubated in a boiling water bath for $30 \mathrm{~min}$. Absorbance was determined at $531 \mathrm{~nm}$. The oxidative stability was expressed in milligrams of MDA per $\mathrm{kg}$ of egg yolk.

The $\mathrm{Al}, \mathrm{TI}$, and $\mathrm{HI}$ indices were calculated from the FA profile using the following equations:

$$
\begin{gathered}
A I=\frac{C 12: 0+4 C 14: 0+C 16: 0}{\sum M U F A+\sum n 6+\sum n 3}(\text { Ulbricht \& Southgate, 1991) } \\
T I=\frac{C 14: 0+C 16: 0+C 18: 0}{0.5 \sum M U F A+0.5 \sum n 6+3 \frac{\sum n 3}{\sum n 6}}(\text { Ulbricht \& Southgate, 1991) } \\
H I=\frac{C 18: 1+C 18: 2+C 18: 3+C 20: 4+C 20: 5+C 22: 6}{C 14: 0+C 16: 0}(\text { Fernandez et al., 2007) }
\end{gathered}
$$

Where: C12:0, C14:0, C16:0, and C18:0 are lauric, myristic, palmitic, and stearic saturated FAs; $\mathrm{C} 18: 1, \mathrm{C} 18: 2, \mathrm{C} 18: 3 \mathrm{C} 20: 4, \mathrm{C} 20: 5$, and $\mathrm{C} 22: 6$ are oleic, linoleic, alinoleic, arachidic, eicosapentaenoic (EPA), and docosahexaenoic (DHA) unsaturated FAs;

n3 FA acids are $\alpha$-linolenic acid, EPA and DHA; and

n6 FAs include linoleic, gamma-linolenic, calendic, eicosadienoic, dihomo-gamma-linolenic, arachidonic, docosadienoic, adrenic, osbond, tetracosatetraenoic, and tetracosapentaenoic acids.

The data measures at a single time were analysed by analysis of variance with the production system as principal effect (SAS Software, version 8.2. SAS Institute, Inc., Cary, NC). For FA content, retinol, $\alpha$ tocopherol and MDA of yolk, the analysis of variance included the main effects of the production system and storage day, and their interaction. When effect was found to be significant, Duncan's multiple range test was used to compare the means. In addition, Pearson correlations were used to evaluate relationships between egg yolk oxidative stability (MDA values) and content of retinol, $\alpha$-tocopherol, and PUFAs and storage time. All the differences were significant at $P<0.05$.

\section{Results and Discussion}


The conventional and organic mixed diet had a higher n-6 FA content owing to the inclusion of sunflower oil, lupine seed and corn (rich in linoleic acid, C18:2 n-6) (Küçükyılmaz et al., 2012), whereas the pasture showed a greater content of n-3 FAs (particularly a-linolenic acid orC18:3n-3) (Table 2). This FA profile resulted in a higher $n-6 / n-3$ ratio in the feed than in the grass. These findings agree with those of Mugnai et al. (2013), who reported that the FA composition of green forages was characterized by a high percentage of $n-3$ FAs, represented mainly by $\alpha$-linolenic acid. In the current study, grass was found to contain approximately seven times more $\alpha$-tocopherol and more than twenty times $\beta$-carotene than the commercial feed. Thus, consumption of $\alpha$-tocopherol, $\beta$-carotene, and C183 n-3 may have increased with the availability of pasture.

Table 2 Fatty acid composition and antioxidant content of conventional and organic diets and grass for Tetra-SL LL laying hens

\begin{tabular}{lcrr}
\hline & Conventional diet & Organic diet & Grass \\
\hline Fatty acids (\%) & & & \\
C16:0, palmitic acid & 15.21 & 14.10 & 15.91 \\
C16:1, palmitoleic acid & 0.42 & 0.51 & 0.23 \\
C18:0,stearic acid & 6.12 & 5.43 & 1.37 \\
C18:1 n-9, oleic acid & 27.18 & 31.51 & 5.82 \\
C18:3 n-3, $\alpha$-linoleic acid & 3.68 & 4.43 & 55.84 \\
C18:2 n-6, linoleic acid & 46.78 & 43.59 & 18.78 \\
C20:4 n-6,arachidonic acid & 0.10 & 0.09 & 0.17 \\
FA n-6 & 46.88 & 43.68 & 18.96 \\
FA n-6/n-3 & 11.93 & 10.54 & 1.34 \\
Antioxidants, mg/kg DM & & & \\
$\alpha-T o c o p h e r o l$ & 25.34 & 181.70 \\
$\beta-c a r o t e n e$ & 1.18 & 2.76 & 27.61
\end{tabular}

FA n-6:polyunsaturated fatty acids that have a final carbon-carbon double bond in the n-6 position, FA n3:polyunsaturated fatty acids that have a final carbon-carbon double bond in the $n-3$ position

Eggs produced by hens in the FR and ORG systems were lighter $(P<0.05)$, while the percentage of yolk was statistically higher in comparison with eggs from hens that were reared in the CON system. Castellini et al. (2006) observed that because of increased motor activity of hens in an organic production system and concomitant lower energy and protein intake resulting from grass replacing grains, the weight of eggs produced in that system was reduced. In contrast, Küçükyılmaz et al. (2012) showed that an organic rearing system led to increased egg weight compared with a conventional rearing system. Finally, Mugnai et al. (2009) reported that the weight of eggs was not affected by production system in a similar study. In accordance with the results of this study, Küçükyılmaz et al. (2012) reported that yolk made up a greater proportion of the egg when the hens were managed in an organic rearing system than in cages. The higher percentage of egg yolk was attributed to dietary intake of grass and insects by Küçükyılmaz et al. (2012). The effects of production system on egg quality parameters are presented in Table 3.

The albumen percentage was the highest in eggs from conventional system $(P<0.01)$, in accordance with Galic et al. (2019). According to Castellini et al. (2006), albumen deposition is greatly affected by the level of dietary protein. Hens housed in CON have continuous access to a balanced diet that meets their requirements and therefore produce an egg of higher weight and albumen content (Lordelo et al., 2017). Hens in the FR and ORG systems may consume less protein by ingesting a large amount of grass. The yolk to albumen ratio in eggs produced in the FR and ORG systems was higher $(P<0.01)$ than in conventionally produced eggs. The present results agree with those of Rizzi and Marangon (2012), who observed a negative correlation between yolk to albumen ratio and egg weight. Galic et al. (2019) found egg weight was highly correlated with albumen weight. The shell constituted a smaller $(P<0.05)$ percentage of egg weight for hens in CON than those in the FR and ORG systems. This could be owing to ingestion of more mineral and higher synthesis of vitamin $D_{3}$ because of greater exposure to sunlight in the FR and ORG groups (Castellini et al., 2006). 
Table 3 Effect of production systems on characteristics of egg quality from Tetra-SL LL laying hens

\begin{tabular}{|c|c|c|c|c|c|c|}
\hline \multirow{2}{*}{\multicolumn{2}{|c|}{ Item }} & \multicolumn{3}{|c|}{ Production systems ${ }^{1}$} & \multirow{2}{*}{ SEM } & \multirow{2}{*}{ Significance } \\
\hline & & CON & $\mathrm{FR}$ & ORG & & \\
\hline \multicolumn{2}{|c|}{ Egg weight (g) } & $58.23^{a}$ & $57.09^{a b}$ & $56.16^{\mathrm{b}}$ & 0.38 & $P<0.05$ \\
\hline \multicolumn{2}{|c|}{ Egg components: yolk (\%) } & $24.27^{b}$ & $25.81^{a}$ & $25.92^{a}$ & 0.19 & $P<0.01$ \\
\hline & albumen (\%) & $65.50^{\mathrm{a}}$ & $62.70^{\mathrm{b}}$ & $62.69^{b}$ & 0.32 & $P<0.01$ \\
\hline & shell (\%) & $10.23^{b}$ & $11.49^{a}$ & $11.39^{a}$ & 0.07 & $P<0.05$ \\
\hline \multicolumn{2}{|c|}{ Yolk/albumen ratio (\%) } & $0.37^{b}$ & $0.41^{\mathrm{a}}$ & $0.41^{\mathrm{a}}$ & 0.008 & $P<0.01$ \\
\hline \multicolumn{7}{|c|}{ Chemical composition of yolk } \\
\hline & crude proteins (\%) & 14.46 & 15.21 & 14.93 & 0.14 & $P>0.05$ \\
\hline & crude fat (\%) & 24.36 & 24.58 & 25.02 & 0.23 & $P>0.05$ \\
\hline \multirow[t]{2}{*}{ Cholesterol: } & $\mathrm{mg} / \mathrm{g}$ of yolk & 14.04 & 13.39 & 14.05 & 0.51 & $P>0.05$ \\
\hline & mg/yolk egg & 198.6 & 197.3 & 212.4 & 2.07 & $P>0.05$ \\
\hline \multicolumn{2}{|c|}{ Retinol ( $\mu \mathrm{g} / \mathrm{g}$ of yolk) } & $4.87^{\mathrm{c}}$ & $9.67^{b}$ & $14.32^{\mathrm{a}}$ & 0,68 & $P<0.001$ \\
\hline \multicolumn{2}{|c|}{$\alpha$-Tocopherol ( $\mu \mathrm{g} / \mathrm{g}$ of yolk) } & $52.4^{c}$ & $77.3^{\mathrm{b}}$ & $98.7^{a}$ & 5,12 & $P<0.001$ \\
\hline
\end{tabular}

a,b,c Within a row, means with a common superscript do not differ at $P<0.05$

${ }^{1} \mathrm{CON}$ : conventional system, FR: free-range system, ORG: organic system

The chemical composition of egg yolk and cholesterol content was not affected by the rearing system. However, retinol and tocopherol were significantly higher in eggs produced by FR and ORG hens (Table 3). These results confirm many previous reports (Küçükyılmaz et al., 2012; Sokołowicz et al., 2018) that rearing system had no effect on egg yolk cholesterol concentration. However, they differ from the findings of Minelli et al. (2007), who indicated that egg yolk cholesterol concentration was lower when the hens were raised in a conventional system. Rizzi et al. (2006) stated that it was difficult to influence the chemical composition of eggs when the dietary needs of the hens were met.

The present study confirmed the ability of hens to transfer $a$-tocopherol and other bioactive compounds from grass and feed to their eggs (Mugnai et al., 2013). The higher retinol content in yolk from FR and ORG hens is because the grass provided additional $\beta$-carotene, which is a precursor of retinol. The dependency between vitamin content of feeds and in eggs has been demonstrated by Zang et al. (2011).

The FA profile of egg yolks was characterized by a relatively low proportion of saturated FAs (SFAs), and higher proportions of MUFAs and PUFAs (Table 4). The production system had no effect on the proportion of SFAs and unsaturated FAs (UFAs) in the egg yolks $(P>0.05)$. For MUFAs and PUFAs, the impact of the production system was statistically significant $(P<0.01)$. The highest level of MUFAs and the lowest level of PUFAs were characteristic of egg yolks from FR and ORG hens $(P<0.01)$. The percentage of PUFA n- 6 was highest in egg yolks from hens in CON $(P<0.01)$, reflecting the higher concentration of $C 18: 2$ n-6 in their feed. Studies by Lordelo et al. (2017) and Sokołowicz et al. (2018) demonstrated that the content of PUFA n-6 FAs in eggs produced in free-range and organic systems was lower than in eggs from a cagehousing system. Eggs from hens in the FR and ORG groups had a higher concentration of PUFA n-3 than those in the CON group, mainly because of higher percentages of C18:3n-3,C20:5n-3, C22:5 n-3, and C22:6 n-3reflecting the higher concentration of C18:3 n-3 in the grass.

The various levels of PUFA $n-3$ and PUFA n- 6 precursors determined modifications of their derivatives. A high level of C18:2 n-6 resulted in an increase in C20:4 n-6 (CON group). In the FR and ORG groups, the higher presence of $C 18: 3 n-3$ favoured synthesis of $C 20: 5 n-3, C 22: 5 n-3$, and C22:6n-3. These results confirmed the efficacy of the hens' enzymatic capability to elongate and desaturate $\alpha$-linolenic acid producing n-3 long-chain PUFAs (Mugnai et al., 2009; 2013), which are then transferred to their eggs. Mugnai et al. (2013) also observed higher levels of $n-3$ long-chain PUFAs in eggs produced by hens in organic systems compared with those in conventional systems.

Similar to the results of this study, Lopez-Bote et al. (1998) reported that eggs produced by hens in the free-range system had higher omega-3 (2.6-fold) and lower omega- 6 contents compared with the conventional system. They attributed this to the availability of pasture that was rich in omega- 3 and low in 
omega-6 FAs. Eggs produced in the ORG system had a higher omega-3 compared with those from the CON system, but were similar to eggs from the FR system $(P>0.05)$, despite the hens in the ORG system having a larger area of pasture as a source of n-3 FAs. The higher PUFA n-3 content of eggs produced in the FR and ORG systems could be associated with outdoor access, because factors that increased the proportion of PUFA n-3 in egg yolk included consumption of fresh grass and invertebrates (Campos et al., 2016; Małgorzata et al., 2017). Green forage is a source of relatively large amounts of n-3 Fas and fat-soluble nutrients, which can ultimately be transferred into the yolk (Sokołowicz et al., 2018; Krawczyk et al., 2013). These results highlight the functional similarities of the eggs from these systems of production.

Table 4 Effect of production systems on the fatty acid profile of egg yolks in Tetra-SL LL laying hens

\begin{tabular}{|c|c|c|c|c|c|}
\hline & \multicolumn{3}{|c|}{ Production systems ${ }^{1}$} & \multirow{2}{*}{ SEM } & \multirow{2}{*}{ Significance } \\
\hline & CON & FR & ORG & & \\
\hline \multicolumn{6}{|l|}{ Fatty acid, \% fatty acid methyl esters } \\
\hline C12:0,lauric acid & 0.07 & 0.06 & 0.07 & 0.001 & $P>0.05$ \\
\hline C14:0,myristic acid & 0.64 & 0.62 & 0.63 & 0.023 & $P>0.05$ \\
\hline C16:0,palmitic acid & 27.28 & 27.73 & 28.08 & 0.252 & $P>0.05$ \\
\hline C18:0,stearic acid & 9.13 & 9.48 & 9.27 & 0.174 & $P>0.05$ \\
\hline C16:1, palmitoleic acid & 2.07 & 2.31 & 2.54 & 0.053 & $P>0.05$ \\
\hline C18:1 n-9,oleic acid & $38.18^{b}$ & $40.61^{\mathrm{a}}$ & $40.03^{a}$ & 0.893 & $P<0.05$ \\
\hline C18:2 n-6, linoleic acid & $16.93^{a}$ & $13.02^{b}$ & $12.67^{b}$ & 0.751 & $P<0.01$ \\
\hline C18:3 n-3, $\alpha$-linolenic acid & $1.67^{c}$ & $1.98^{\mathrm{b}}$ & $2.61^{\mathrm{a}}$ & 0.084 & $P<0.001$ \\
\hline C18:3 n-6, y-linolenic acid & 0.21 & 0.18 & 0.20 & 0.011 & $P>0.05$ \\
\hline C20:4 n-6, arachidonic acid & $2.70^{\mathrm{a}}$ & $1.62^{\mathrm{b}}$ & $1.70^{\mathrm{b}}$ & 0.031 & $P<0.05$ \\
\hline C20:5 n-3,eicosapentaenoic acid & $0.47^{b}$ & $0.71^{a}$ & $1.06^{\mathrm{a}}$ & 0.092 & $P<0.01$ \\
\hline C22:5 n-3, docosapentaenoic acid & $0.18^{b}$ & $0.37^{a}$ & $0.42^{\mathrm{a}}$ & 0.027 & $P<0.01$ \\
\hline C22:6 n-3, docosahexaenoic acid & $0.64^{b}$ & $1.31^{a}$ & $1.72^{\mathrm{a}}$ & 0.078 & $P<0.01$ \\
\hline Other fatty acids & 1.23 & 1.76 & 1.87 & 0.018 & $P>0.05$ \\
\hline$\sum$ Saturated fatty acids & 37.12 & 37.89 & 38.05 & 0.221 & $P>0.05$ \\
\hline$\Sigma$ Unsaturated fatty acids & 61.65 & 60.58 & 60.58 & 0.237 & $P>0.05$ \\
\hline$\Sigma$ Monounsaturated fatty acids & $40.25^{b}$ & $42.92^{\mathrm{a}}$ & $42.57^{a}$ & 0.411 & $P<0.01$ \\
\hline$\sum$ Polyunsaturated fatty acids & $21.40^{\mathrm{a}}$ & $17.64^{\mathrm{b}}$ & $18.01^{b}$ & 0.356 & $P<0.01$ \\
\hline$\sum \mathrm{n}-6$ fatty acids & $19.84^{a}$ & $14.82^{\mathrm{b}}$ & $14.57^{b}$ & 0.398 & $P<0.01$ \\
\hline$\sum \mathrm{n}-3$ fatty acids & $1.56^{\mathrm{b}}$ & $2.81^{\mathrm{a}}$ & $3.44^{\mathrm{a}}$ & 0.017 & $P<0.01$ \\
\hline
\end{tabular}

a,b,c Within a row, means with a common superscript do not differ at $P<0.05$

${ }^{1}$ CON: conventional system, FR: free-range system, ORG: organic system

$\mathrm{n}-6$ : polyunsaturated fatty acids that have a final carbon-carbon double bond in the $n-6$ position, $n-3$ : polyunsaturated fatty acids that have a final carbon-carbon double bond in the n-3 position

Dietary intake of $n-3$ FAs is associated with reduced risk of pathologies such as cardiovascular and neurodegenerative diseases (Simopoulos, 2000). The PUF to SFA and n-6 to n-3 FA ratios, and Al, TI and $\mathrm{HI}$ are commonly used to assess the effects of lipids on consumer health (Table 5). In general, a ratio of PUFAs to SFAs above 0.45 is required in human diets to combat 'lifestyle diseases', such as coronary heart disease and cancer (Simopoulos, 2000). Because they contain more PUFAs, eggs from the CON system have a better PUFA to SFA ratio, compared with those from the FR and ORG systems. Food with lower PUFA to SFA ratio can induce an increase of blood cholesterol (Simopoulos, 2000). When analysed alone, this ratio may have restrictions, since it relies only on chemical structure of the FAs, since all SFAs can induce the increase of blood cholesterol, thus ignoring the hypocholesterolemic effects of MUFAs and the PUFA profile of egg yolks (Melo et al., 2019). 
In the current study, the n- 6 to n-3 FA ratio was more favourable in eggs from the ORG and FR systems than in those from the CON system. Because the optimal n- 6 to n-3 ratio is between 4 and 10 , eggs with a higher content of n-3 PUFAs and thus a lower $n-6$ to $n-3$ PUFA ratio are considered health-promoting with anti-cancer and anti-atherogenic properties (Simopoulos, 2000). The values of AI, TI and $\mathrm{HI}$ of yolks in this study were comparable with the results of Attia et al. (2015) and Małgorzata et al. (2017). The eggs from the ORG and FR systems had lower $\mathrm{TI}$ and $\mathrm{HI}$ than eggs from the CON system, but differences were not significant. The Al, TI, and $\mathrm{HI}$ are considered markers of fat quality (Mugnai et al., 2013). Eggs with low values of $\mathrm{Al}, \mathrm{TI}$, and $\mathrm{HI}$ are good for retarding atherosclerosis and thus reducing the risk of cardiovascular disorders (Simopoulos, 2000).

With increasing the PUFA content of eggs, there is a concomitant increase in the susceptibility to oxidative deterioration of eggs, leading to losses in quality characteristics and nutritional value, lower consumer acceptability and deleterious biological effects (Addis \& Park, 1989). Some reports indicated that n-3 FAs were particularly susceptible to lipid oxidation, and even small differences in the concentration of these FAs may be critically important in the development of oxidation (Lopez-Bote et al., 1998).

Table 5 Effect of production systems on the indices of nutritional quality of lipids from egg yolks from TetraSL LL laying hens

\begin{tabular}{|c|c|c|c|c|c|}
\hline \multirow{2}{*}{ Item } & \multicolumn{3}{|c|}{ Production systems ${ }^{1}$} & \multirow{2}{*}{ SEM } & \multirow{2}{*}{ Significance } \\
\hline & CON & FR & ORG & & \\
\hline PUFA/SFA & $0.57^{\mathrm{a}}$ & $0.47^{b}$ & $0.47^{b}$ & 0.014 & $P<0.01$ \\
\hline$n-6 / n-3$ ratio & $12.72^{\mathrm{a}}$ & $5.27^{b}$ & $4.23^{c}$ & 0.187 & $P<0.001$ \\
\hline Atherogenicity index & 0.49 & 0.50 & 0.51 & 0.017 & $P>0.05$ \\
\hline Thrombogenicity index & 1.07 & 1.01 & 0.97 & 0.011 & $P>0.05$ \\
\hline Hypocholesterolaemic index & 2.18 & 2.11 & 2.10 & 0.978 & $P>0.05$ \\
\hline Linoleic acid to $\alpha$-linolenic acid ratio & $9.90^{\mathrm{a}}$ & $6.57^{\mathrm{b}}$ & $4.85^{\mathrm{c}}$ & 0.218 & $P<0.001$ \\
\hline
\end{tabular}

a,b,c Within a row, means with a common superscript do not differ at $P<0.05$

${ }^{1}$ CON: conventional system, FR: free-range system, ORG: organic system

$\mathrm{n}-6$ : polyunsaturated fatty acids that have a final carbon-carbon double bond in the $n-6$ position, $n-3$ : polyunsaturated fatty acids that have a final carbon-carbon double bond in the $n-3$ position

The thiobarbituric acid reactive substances in fresh and stored eggs (15 and 30 days) were higher ( $P$ $<0.01)$ in eggs from hens raised in the CON system than in those from hens in the FR and ORG systems (Table 6). Cherian et al. (1996) reported that TBARS values were higher in fresh eggs with a greater content of $n-3$ FAs than in those that were rich in n-6 FAs. Because of this concentration of n-3 FAs, greater susceptibility to lipid peroxidation of the egg yolk was expected in those from hens in FR and ORG. Malonaldehyde, a lipid peroxidation biomarker, was higher in eggs from the CON system and this concurred with the higher FA n-6 and lower retinol and $\alpha$-tocopherol contents of the eggs. The lower than expected oxidation, based on the n-3 FA composition, is notable of eggs from hens in the FR and ORG groups. It may be attributed to the higher concentration of a-tocopherol and retinol in the egg yolks $(P<0.001)$. The increased antioxidant content for eggs from the ORG and FR systems may decrease lipid peroxidation, improve the keeping quality of the eggs during storage, and thus be of benefit to costumers. In agreement with this statement, Lai et al. (1995) observed a reduction of oxidative processes in eggs that were enriched with vitamin $E$ and carotenoids. It has been suggested that there is synergy between these molecules (Wang \& Quinn, 2000).

Raising hens on pasture provided a dietary source of vitamin E, which resulted in the concentration of a-tocopherol in eggs being greater than in those from hens that were kept in cages and fed a conventional diet (Lopez-Bote et al., 1998). In recent years, the antioxidant effect on eggs of dietary natural antioxidants has been shown (Lopez-Bote et al., 1998; Mugnai et al., 2013). Malonaldehyde was present in yolks of fresh eggs and could be attributed to consumption and subsequent deposition of MDA from the diet or to in vivo production of MDA by the hens during the trial (Shahryar et al., 2010). The former possibility appeared unlikely because the level of MDA would have been equal among all treatments. Possible transfer of the antioxidant constituents of the diets might inhibit the chain reaction involved in oxidation of the consumed lipids, thus decreasing the oxidation products transferred into the yolk. 
Table 6 Effects of different production systems on antioxidant retinol and $\alpha$-tocopherol content and thiobarbituric acid reactive substances during storage of eggs from Tetra-SL LL laying hens

\begin{tabular}{|c|c|c|c|c|c|c|c|c|}
\hline \multirow{2}{*}{ Content of yolk } & \multirow{2}{*}{$\begin{array}{l}\text { Storage } \\
\text { time (days) }\end{array}$} & \multicolumn{3}{|c|}{ Production systems (PS) ${ }^{1}$} & \multirow{2}{*}{ SEM } & \multicolumn{3}{|c|}{ Significance } \\
\hline & & $\mathrm{CON}$ & $\mathrm{FR}$ & ORG & & PS & $S$ & $P S \times S$ \\
\hline \multirow{3}{*}{$\begin{array}{l}\text { Retinol, } \mu \mathrm{g} / \mathrm{g} \text { of } \\
\text { yolk }\end{array}$} & 0 & $4.87^{c x}$ & $9.67^{\mathrm{bx}}$ & $14.32^{\mathrm{ax}}$ & \multirow{3}{*}{0.453} & \multirow{3}{*}{$P<0.001$} & \multirow{3}{*}{$P<0.05$} & \multirow{3}{*}{$P<0.05$} \\
\hline & 15 & $3.41^{\mathrm{cy}}$ & $6.43^{\text {by }}$ & $8.04^{\text {ay }}$ & & & & \\
\hline & 30 & $3.27^{c y}$ & $5.75^{\text {by }}$ & $7.70^{\text {ay }}$ & & & & \\
\hline \multirow{3}{*}{$\begin{array}{l}\alpha \text {-Tocopherol, } \\
\mu \mathrm{g} / \mathrm{g} \text { of yolk }\end{array}$} & 0 & $52.4^{\mathrm{cx}}$ & $77.3^{\mathrm{bx}}$ & $98.7^{\mathrm{ax}}$ & \multirow{3}{*}{1.274} & \multirow{3}{*}{$P<0.01$} & \multirow{3}{*}{$P<0.01$} & \multirow{3}{*}{$P>0.05$} \\
\hline & 15 & $47.1^{\mathrm{cx}}$ & $74.8^{\mathrm{bx}}$ & $84.2^{\mathrm{ay}}$ & & & & \\
\hline & 30 & $33.8^{\mathrm{cy}}$ & $58.2^{\text {by }}$ & $68.6^{\mathrm{az}}$ & & & & \\
\hline \multirow{3}{*}{$\begin{array}{l}\text { TBARS, } \\
\mathrm{mg} \mathrm{MDA} / \mathrm{kg} \text { of } \\
\text { egg yolk }\end{array}$} & 0 & $0.432^{\text {ay }}$ & $0.324^{\text {by }}$ & $0.294^{\text {by }}$ & \multirow{3}{*}{0.074} & \multirow{3}{*}{$P<0.01$} & \multirow{3}{*}{$P<0.001$} & \multirow{3}{*}{$P<0.05$} \\
\hline & 15 & $0.874^{a x}$ & $0.478^{b x}$ & $0.405^{b x}$ & & & & \\
\hline & 30 & $0.915^{\mathrm{ax}}$ & $0.520^{b x}$ & $0.427^{b x}$ & & & & \\
\hline
\end{tabular}

a,b,c Means within a row with a common superscript do not differ at $P<0.05$

$x, y$ Within a trio of means for a characteristic and PS, means with a common superscript do not differ at $P<0.05$

${ }^{1} \mathrm{CON}$ : conventional system, FR: free-range system, ORG: organic system

S: storage time, TBARS: thiobarbituric acid reactive substances; MDA: malonaldehyde

The correlation analysis showed the potential relationship between PUFAs and retinol and tocopherol content and lipid oxidation of storage eggs (Table 7). The most important observation is the presence of a positive relationship of $n-3$ FAs with MDA, indicating that an increase of $n-3$ FA level accompanies an increase in MDA $(P<0.01)$. In addition, negative correlations of MDA concentration with retinol and $\alpha$ tocopherol levels in the yolk indicated that carotenes and tocopherols from fresh grass have positive potential as natural antioxidants and could contribute to preventing lipid oxidation in egg yolks.

Table 7 Correlation between oxidative stability (concentration of malonaldehyde), storage time and content of polyunsaturated fatty acids and antioxidant retinol and $\alpha$-tocopherol content in egg yolks

\begin{tabular}{cccc}
\hline \multicolumn{1}{c}{ Correlation } & Pearson's & correlation coefficient & $P$-value \\
\hline \multirow{4}{*}{ Storage time } & 0.1523 & 0.087 \\
& PUFAs & 0.5791 & $<0.05$ \\
& FA n-6 & 0.2372 & 0.129 \\
& FA n-3 & 0.8641 & $<0.01$ \\
& Retinol & -0.4136 & $<0.05$ \\
& a-Tocopherol & -0.6719 & $<0.01$
\end{tabular}

MDA: malonaldehyde; PUFAs: polyunsaturated fatty acids; FAs: fatty acids

\section{Conclusions}

Variation in the quality of eggs exists when hens are kept in CON, FR, and ORG production systems. The FA composition of the yolk was affected significantly by access to pasture. Access of hens to pasture in the FR and ORG production systems provided a good source of FA n-3 and antioxidants, which improved the oxidative stability of lipids in egg yolk. However, the small differences that were observed between the FR and ORG production systems are unlikely to have effects that can be detected by the consumer. The improved FA profile of eggs from FR and ORG may counterbalance the loss of egg weight. Some 
constituents of grass may be of interest to produce eggs that are rich in n-3 FAs, retinol and a-tocopherol, which increase the quality without adverse oxidative effects.

\section{Acknowledgements}

This research was conducted in the context of project PN-II-IN-Cl-2012-1-0257. The research study was funded partially by Rosbro Avicom SRL, Bihor, Romania. The author would like to thank the staff of Marcela Laza for their collaboration during the experimental period.

\section{Conflict of Interest Declaration}

The author declares that there was no conflict of interest.

\section{References}

Addis, P.B. \& Park, S.W., 1989. Role of lipid oxidation products in atherosclerosis. In: R. Scanlan \& S.L. Taylor (eds.), Food Toxicology. Marcel Dekker, New York, NY. Pp. 297-330.

Anderson, K.E., 2011. Comparison of fatty acid, cholesterol, and vitamin A and E composition in eggs from hens housed in conventional cage and range production facilities. Poult. Sci. 90, 1600-1608.

AOAC (Association of Official Analytical Chemists), 1999. Methods of analysis, 16th edition.

Attia, Y.A., AL-Harthi, M.A., Korish, M.A. \& Shiboob, M.M., 2015. Fatty acid and cholesterol profiles and hypocholesterolemic, atherogenic, and thrombogenic indices of table eggs in the retail market. Lipids Health Dis. 14 (136), 1-8.

Campos, A.M., Ricardo, F., Alves, E., Reis, A., Couto, D., Domingues, P. \& Domingues, M.R.M., 2016. Lipidomic investigation of egg yolks: Changes in lipid profile of eggs from different conditions. Food Res. Int. 89, 177-185

Castellini, C., Perella, F., Mugnai, C. \& Dal Bosco, A., 2006. Welfare, productivity and qualitative traits of egg in laying hens reared under different rearing systems. Poster at XII European Poultry Conference, Verona, 10-14 September 2006

Cherian, G., Wolfe, F.H. \& Sim, J.S., 1996. Dietary oils with added tocopherols: effects on egg or tissue tocopherols, fatty acids and oxidative stability. Poult. Sci. $75,423-431$.

European Union (EU), 2007. Directive 834/2007/EC, 28 June 2007. Organic production and labelling of organic products. Official Journal of the European Communities L189, 1-23.

European Union (EU), 1999. EC no 1804/99 of July 1999 supplementing regulation (EEC) no 2092/91 on Organic Production of Agricultural Products. Off. J. Lett. 222 of 08/24/1999. pp. 1-28

Fernández, M., Ordóñez, J.A., Cambero, I., Santos, C., Pin, C. \& De la Hoz, L., 2007. Fatty acid compositions of selected varieties of Spanish dry ham related to their nutritional implications. Food Chem. 9, 107-112.

Folch, J., Lees, M. \& Stanley, G.H.S., 1957. A simple method for the isolation and purification of total lipid from animal tissues. J. Biol. Chem. 226, 497-509.

Galic, A., Filipovic, D., Janjecic, Z., Bedekovic, D., Kovacev, I., Copec, K. \& Pliestic S., 2019. Physical and mechanical characteristics of Hisex Brown hen eggs from three different housing systems. S. Afr. J. Anim. Sci. 49(3), 468476.

Krawczyk, J., Sokołowicz, Z., Świątkiewicz, S. \& Sosin-Bzducha, E., 2013. Effect of outdoor access and increased amounts of local feed materials in the diets of hens covered by the gene-pool protection program for farm animals in Poland on quality of eggs during peak egg production. Ann. Anim. Sci. 13 (2), 327-339.

Kücükyilmaz, K., Bozkur, M., Herken, E.N., Cinar, M., Catli, A.U., Bintas, E. \& Coven, F., 2012. Effects of rearing systems on performance, egg characteristics and immune response in two layer hen genotypes. AsianAustralasian J. Anim. Sci. 25 (4), 559-568.

Lai, S.M., Gray, J.I., Buckley, J.D. \& Kelly, P.M., 1995. Influence of free radicals and other factors on formation of cholesterol oxidation products in spray-dried whole egg. J. Agric. Food Chem., 72, 1127-1131.

Lopez-Bote, C.J., Sanz Arias, A.I., Rey, A.I., Castano, A., Isabel, B. \& Thos, J., 1998. Effect of free-range feeding on n-3 fatty acid and $\alpha$-tocopherol content and oxidative stability of eggs. Anim. Feed Sci. Technol.,72, 33-38.

Lordelo, M., Fernandes, E., Bessa, R.J.B. \& Alves, S.P., 2017. Quality of eggs from different laying hen production systems, from indigenous breeds and specialty eggs. Poult. Sci. 96(5), 1485-1491.

Małgorzata, G., Krawczyk, J. \& Otwinowska-Mindur, A., 2017. Effect of production cycle and season on quality and fatty acid profile of organic eggs from local Polish Greenleg Partridge hens. Europ. Poult. Sci., 81. DOI: 10.1399/eps.2017.188.

Melo, J., Ferreira, F., Labre da Silva, T., Nascimento, K., de Oliveira V., Barbosa, J.L., Barbosa, M. \& Saldanha, T., 2019. Nutritional quality and functional lipids in the free-range egg yolks of Brazilian family farmers. Rev. Chil. Nutr. 46(4), 420-428.

Mierliță, D., 2019. Fatty acids profile and oxidative stability of eggs from laying hens fed diets containing hemp seed or hempseed cake. S. Afr. J. Anim. Sci. 49(2), 310-321.

Mierliță, D., Pop, I.M., Teușdea, A., Lup, F., Dărăban, S., Georgescu, B., Boaru, A. \& Rahmann, G., 2017. Effect of forage preservation method on fatty acid composition and oxidative stability of organic sheep milk. Landbauforsch Appl.Agric.Forestry Res. 67(1), 43-52.

Minelli, G., Sirri, F., Folegatti, E., Meluzzi, A. \& Franchini, A., 2007. Egg quality traits of laying hens reared in organic and conventional systems. It. J. Anim. Sci. 6(1), 728-730. 
Moyle, J.R., Arsi, K., Woo-Ming, A., Arambel, H., Fanatico, A., Blore, P.J., Clark, F.D., Donoghue, D.J. \& Donoghue, A.M., 2014. Growth performance of fast-growing broilers reared under different types of production systems with outdoor access: Implications for organic and alternative production systems. J. Appl. Poult. Res. 23, 212-220.

Mugnai, C., Dal Bosco, A. \& Castellini, C., 2009. Effect of rearing system and season on the performance and egg characteristics of Ancona laying hens. It. J. Anim. Sci. 8, 175-188.

Mugnai, C., Sossidou, E.N., Dal Bosco, A., Ruggeri, S., Mattioli, S. \& Castellini C., 2013. The effects of husbandry system on the grass intake and egg nutritive characteristics of laying hens. J. Sci. Food Agric. 94(3), 459-467.

Rizzi, C. \& Marangon, A., 2012. Quality of organic eggs of hybrid and Italian breed hens. Poult. Sci. 91, $2330-2340$.

Rizzi, L., Simioli, G., Martelli, G., Paganelli, R. \& Sardi, L., 2006. Effects of organic farming on egg quality and welfare of laying hens. XII European Poultry Conference, 10 - 14 September 2006, Verona, Italy.

Shahryar, H.A., Salamatdoust, R., Chekani-Azar, S., Ahadi, F. \& Vahdatpoor, T., 2010. Lipid oxidation in fresh and stored eggs enriched with dietary $\omega 3$ and $\omega 6$ polyunsaturated fatty acids and vitamin $E$ and A dosages. Afr. J. Biotechnol. 9(12), 1827-1832.

Simopoulos, A.P., 2000. Symposium: Role of poultry products in enriching the human diet with n-3 PUFA. Poult. Sci. 79 , 961-970.

Sokołowicz, Z., Krawczyk, J. \& Dykiel, M., 2018. Effect of alternative housing system and hen genotype on egg quality characteristics. Emir. J. Food Agric. 30(8), 695-703.

Tetra SL LL, 2017. Commercial management guide. Bábolna Tetra Ltd., Radnóti, Hungary.

Tufarelli, V., Ragni, M. \& Laudadio, V., 2018. Feeding forage in poultry: A promising alternative for the future of production systems. Agriculture 8(6), 81.

Ulbricht, T.L.V. \& Southgate, D.A.T., 1991. Coronary heart disease: Seven dietary factors. Lancet 338, 985-992.

Wang, X. \& Quinn P.J., 2000. The location and function of vitamin E in membranes (Review). Mol. Membr. Biol.17, 143156.

Washburn, K.W. \& Nix, D.F., 1974. A rapid technique for extraction of yolk cholesterol. Poult. Sci. 53, 1118-1122.

Wynn, C., Williams, T., Allen, O. \& Inserra, P., 2016.Cholesterol content and health effects in free range, organic and conventionally raised poultry and eggs. Human Health Handbooks 11, 179-190.

Zang, H., Zhang, K., Ding, X., Bai, S., Hernandez, J. \& Yao, B., 2011. Effects of different dietary vitamin combinations on the egg quality and vitamin deposition in the whole egg of laying hens. Rev. Bras. Cienc. Avic. 13, 189-196. 